(2) Open Access Full Text Article

\title{
Penehyclidine hydrochloride: a potential drug for treating COPD by attenuating Toll-like receptors
}

This article was published in the following Dove Press journal:

Drug Design, Development and Therapy

31 October 2012

Number of times this article has been viewed

\author{
Hong-Tao Xiao',* \\ Zhi Liao ${ }^{2, *}$ \\ Rong-Sheng Tong' \\ 'Department of Pharmacy, \\ 2Department of Gynecology and \\ Obstetrics, Sichuan Academy of \\ Medical Sciences and Sichuan \\ Provincial People's Hospital, Chengdu, \\ China \\ *These authors contributed equally \\ to this work
}

Background: The aim of this review was to evaluate and summarize the available scientific information on penehyclidine hydrochloride (PHC) for the treatment of chronic obstructive pulmonary disease (COPD) as a result of its ability to attenuate Toll-like receptors. Penehyclidine hydrochloride is an anticholinergic drug manufactured in China, with both antimuscarinic and antinicotinic activity. PHC is used widely in the clinic as a reversal agent in cases of organic phosphorus poisoning and soman poisoning, but also may also have an important role as a bronchodilator in the treatment of obstructive airway disease, including asthma and, in particular, COPD.

Methods: Our bibliographic sources included the CAPLUS, MEDLINE, REGISTRY, CASREACT, CHEMLIST, CHEMCATS, and CNKI databases, updated to September 2012. In order to assess the data in detail, we used the search terms "penehyclidine hydrochloride," "COPD," "muscarinic receptor," and "toll-like receptors." Papers were restricted to those published in the English and Chinese languages, and to "paper" and "review" as the document type. Patents were also reviewed.

Results: Our survey mainly yielded the results of research on PHC and the mechanisms of COPD. COPD is a preventable and treatable disease with some significant extrapulmonary manifestations that may contribute to its severity in some patients. Recently, it has been shown that muscarinic receptors may interact with Toll-like receptors. Basic and clinical studies of the relationship between the mechanism of action and the effects of PHC in the respiratory tract have been studied by a number of laboratories and institutions. The main advantages of PHC are that it has few $\mathrm{M}_{2}$ receptor-associated cardiovascular side effects and attenuates Toll-like receptors.

Conclusion: PHC may be a promising candidate agent in the treatment of COPD in the future because of its ability to attenuate Toll-like receptors. This review should be of help to those intending to research this topic further.

Keywords: penehyclidine hydrochloride, chronic obstructive pulmonary disease, Toll-like receptors

\section{Introduction}

Penehyclidine hydrochloride (PHC) or 3-(2'-phenyl-2'-cyclopentyl-2'-hydroxyl-ethoxy) quinuclidine is an anticholinergic drug with both antimuscarinic and antinicotinic activity. It has potent central and peripheral anticholinergic effects. ${ }^{1}$ Currently, PHC is used widely in the clinic in China as a reversal agent in cases of organophosphorus and soman poisoning. ${ }^{2}$ Basic and clinical studies performed in our laboratory and at other institutions ${ }^{3}$ show that the main advantage of $\mathrm{PHC}$ is that it has fewer $\mathrm{M}_{2}$ receptorassociated cardiovascular side effects than other hyoscyamines marketed in China. ${ }^{4}$
Correspondence: Hong-Tao Xiao Department of Pharmacy, Sichuan Academy of Medical Sciences and Sichuan Provincial People's Hospital, No. 32 West Second Section, First Rng Road, Chengdu, Sichuan, China Tel +8628 87393353

Fax +862887393485

Email xht927@।63.com 
In addition to improving the microcirculation, $\mathrm{PHC}$ can inhibit lipid peroxidation, attenuate the release of lysosomes, and depress microvascular permeability. ${ }^{5}$ Moreover, it can significantly decrease expression of brain nuclear transcription factor- $\kappa \mathrm{B}(\mathrm{NF}-\kappa \mathrm{B})$ in cerebral ischemia-reperfusion injury. ${ }^{6}$ Qiao et al studied the pharmacokinetics of PHC in mice after intramuscular administration of PHC 0.05, 0.15, and $0.45 \mathrm{mg} / \mathrm{kg}$, and found that PHC was well absorbed, rapidly distributed, and excreted via urine, mainly as inactive metabolites. $^{7}$

Anticholinergic agents, including PHC, have a role as bronchodilators in the treatment of obstructive airway diseases, including asthma and, more particularly, chronic obstructive pulmonary disease (COPD) ${ }^{8}$ As an antagonist at the cholinergic receptor, $\mathrm{PHC}$ is a candidate drug for the treatment of COPD. Here we present an indepth survey of the available scientific information on the ability of PHC to attenuate Toll-like receptors (TLRs) and its potential role in the treatment COPD. Because our aim was to identify state of the art information, our literature search was restricted to research on PHC.

\section{Materials and methods}

Our bibliographic sources were the SciFinder CAPLUS, MEDLINE, REGISTRY, CASREACT, CHEMLIST, CHEMCATS, and CNKI databases, updated to September 2012. In order to assess the data in detail, we used the search terms "penehyclidine hydrochloride," "COPD," "muscarinic receptor," and "toll-like receptors." Papers were restricted to those published in the English and Chinese languages, and "paper" and "review" as the document type. Patents were also reviewed.

\section{Results and discussion COPD and TLRs}

COPD is a preventable and treatable disease with some significant extrapulmonary components that may contribute to disease severity in individual patients. Its pulmonary component is airflow limitation that is not fully reversible. The airflow limitation is usually progressive and associated with an abnormal inflammatory response of the lung to noxious particles or gases. ${ }^{9}$ The cardinal characteristic of COPD in humans is airway hyperreactivity, with viral infection of the respiratory tract being one of the major causes. The recognition of pathogen-associated molecular patterns expressed by infectious agents, including viruses, involves members of the TLR family that mediate early host defense. ${ }^{10,11}$ To date, 13 members of the TLR family have been identified in the human genome. All members of this superfamily signal in a similar manner, owing to activation of shared molecules such as tumor necrosis factor (TNF)receptor-associated factor 6 (TRAF6), NF- $\kappa \mathrm{B}$, adaptor protein myeloid differentiation factor 88 ([MyD88] except $\mathrm{TLR}_{3}$ ), and mitogen-activated protein kinases. ${ }^{12}$

The TLRs initiate intracellular signaling either dependent on or independent of MyD88. ${ }^{13}$ In the MyD88-dependent pathway, MyD88 recruits and promotes interaction between interleukin-1 receptor-associated kinase (IRAK)-4 and IRAK-1, resulting in phosphorylation and activation of IRAK-1 by IRAK-4. Phosphorylation of IRAK1 induces interaction between TRAF6 and the IRAK complex. TRAF6 triggers activation of the transforming growth factor $\beta$-activated and mitogen-activated protein kinases. Activation of transforming growth factor $\beta$-activated kinase leads to phosphorylation of the inhibitory kappa kinase complex, which catalyzes inhibitory NF- $\mathrm{KB}$ protein phosphorylation and degradation by the proteosome pathway, thereby resulting in translocation of $\mathrm{NF}-\kappa \mathrm{B}$ to the nucleus and ultimately production of a large number of proinflammatory and anti-inflammatory gene products. The other pathway is independent of MyD88, and signals through Toll-interleukin-1R domain-containing adaptor-inducing interferon- $\beta$ (TRIF), leading to phosphorylation of interferon regulatory factor 3 , which translocates to the nucleus and induces expression of interferon- $\beta$ and interferon-inducible gene. It should be stressed that the independent pathway activates NF- $\kappa \mathrm{B}$ in a delayed fashion, leading to production of a range of inflammatory cytokines, including TNF- $\alpha$, interleukin-8, and interleukin-6.

$\mathrm{TLR}_{3}$ has an important role in recognition of doublestranded viral RNA, which leads to production of various inflammatory mediators, so an understanding of $\mathrm{TLR}_{3}$ activation should provide insight into the mechanisms underlying virus-induced exacerbations of pulmonary disease. In one study, $\mathrm{TLR}_{3}$ knockout mice and wild-type C57B6 mice were administered repeated intranasal doses of polyinosinic-polycytidylic acid, a synthetic double-stranded RNA analog. ${ }^{14}$ There was a significant increase in the total number of cells, especially neutrophils, in bronchoalveolar lavage fluid samples from mice treated with polyinosinicpolycytidylic acid. In addition, interleukin-6, chemokine (C-X-C motif) ligand 3, chemokines $\mathrm{KC}$ and JE, granulocyte macrophage colony-stimulating factor, chemokine $(\mathrm{C}-\mathrm{C}$ motif) ligand 3 , chemokine (C-C motif) ligand 5, and TNF were upregulated.

Histological analysis of the lungs revealed a cellular infiltrate in the interstitium and epithelial cell hypertrophy in 
the small bronchioles. In association with the proinflammatory effects of polyinosinic-polycytidylic acid, the mice showed significant impairment of lung function, both at baseline and in response to methacholine challenge as measured by whole body plethysmography and invasive measurement of airway resistance. Importantly, $\mathrm{TLR}_{3}$ knockout mice were protected against changes in lung function induced by polyinosinicpolycytidylic acid at baseline, which correlated with milder inflammation in the lung and significantly reduced epithelial cell hypertrophy. These findings demonstrate that TLR activation by polyinosinic-polycytidylic acid modulates the local inflammatory response in the lung, and suggests a critical role for $\mathrm{TLR}_{3}$ activation in driving impairment of lung function. Thus, $\mathrm{TLR}_{3}$ activation may be one mechanism via which viral infections contribute toward exacerbation of respiratory disease.

TLRs might also be important in COPD because they participate in the defense against viral and bacterial infections in the airways, worsening the disease process in the lungs of patients with COPD. Therefore, targeting communication between epithelial cells, macrophages, monocytes, and neutrophils via modulation of TLRs might lead to potential new therapeutic treatments for COPD.

\section{COPD and muscarinic receptors}

The cholinergic nervous system plays an important role in COPD. Vagally mediated reflex bronchoconstriction is seen after viral infection, exposure to ozone, and inhalation of an antigen. Dysfunction of inhibitory muscarinic $\mathrm{M}_{2}$ receptors on the vagal nerve endings may increase the release of acetylcholine. Because of the increased reflex bronchoconstriction resulting from these asthma triggers, anticholinergics may be particularly useful in the treatment of COPD. ${ }^{15}$ Muscarinic receptors are also involved in the pathogenesis of airway hyperreactivity by mediating constriction of airway smooth muscle both directly and indirectly. Directly, muscarinic $M_{3}$ receptors are the predominant subtype mediating smooth muscle contraction in the airway, and it has been observed that bronchoconstriction induced by vagal nerve stimulation is lost in mice deficient in muscarinic $M_{3}$ receptors. ${ }^{16}$ Indirectly, muscarinic $\mathrm{M}_{2}$ receptors are linked to inhibition of adenylate cyclase activity, and activation of this receptor subtype lowers cyclic AMP levels in tissues and enhances vagally induced bronchoconstriction, most likely because of enhanced acetylcholine release. ${ }^{17}$

Interestingly, acetylcholine is not only a primary parasympathetic neurotransmitter in the airways, exerting its physiological effects via muscarinic receptors, but is also considered to be a factor able to stimulate airway inflammation by promoting activation of bronchial epithelial cells, alveolar macrophages, and inflammatory cells (macrophages, neutrophils, eosinophils, and lymphocytes) in induced sputum from patients with COPD, leading to release of mediators with chemotactic activity from both eosinophils and neutrophils. ${ }^{18}$

Moreover, researchers have identified that innate immunity and inflammation are controlled by the vagus nerve, which is already known to be a regulator of other vital physiological functions. Activation of cholinergic signaling by the vagus nerve inhibits overproduction of TNF and other proinflammatory cytokines via immunerelated $\alpha 7$ nicotinic receptor-mediated mechanisms, so the cholinergic anti-inflammatory pathway is a neural, efferent vagus nerve-based mechanism that controls inflammation. Cholinergic signaling from the vagus nerve interacts with $\alpha 7$ nicotinic acetylcholine receptors on immune cells and inhibits production of TNF and other proinflammatory cytokines, and therefore attenuates the inflammatory response. This pathway can be exploited in the treatment of inflammatory disorders. ${ }^{19}$

The other key characteristic of COPD in the human airway is inflammation. From the above discussion, we can conclude that muscarinic receptors may be involved not only in the process of airway bronchoconstriction but also in the airway inflammation that occurs with COPD. As a result, muscarinic antagonists may help to control the inflammatory process in airway disease.

\section{COPD and PHC}

PHC is a selective anticholinergic drug, and receptor binding assay results show that PHC has greater selectivity for the $M_{3}$ receptor subtype than the $M_{1}$ receptor subtype. ${ }^{20}$ Improved anticholinergic medications based on selective $\mathrm{M}_{3}$ antagonists may be useful in the treatment COPD. ${ }^{21}$ We have investigated PHC in an asthma model using guinea pigs and rabbits, and shown that the antiasthmatic effect of PHC $0.5 \mathrm{mg} / \mathrm{mL}$ aerosol was equivalent to that of isoprenaline $0.5 \mathrm{mg} / \mathrm{mL}$ in vivo. ${ }^{22}$ We have also investigated the effects and mechanisms of $\mathrm{PHC}$ in the respiratory tract using isolated guinea pig trachea and bronchoalveolar lavage fluid to study the bronchodilatory action of PHC in smooth muscle. Our results indicate that the bronchodilatory effect of PHC was greater than that of atropine sulfate in two assays, according to $\mathrm{PA}_{2}$ values and maximal reducing mount index. Radioimmunoassay was used to determine 
cAMP levels in the isolated guinea pig trachea and lung smooth muscle and the selective effects on muscarinic receptor subtypes. Using this assay, PHC was seen to increase cAMP levels in isolated smooth muscle from guinea pig lung and to decrease cAMP levels in smooth muscle isolated from guinea pig trachea, but this difference was not statistically significant at a dose of $10 \mu \mathrm{mol} / \mathrm{L}$. Our findings suggest that $\mathrm{PHC}$ has little or no effect on $\mathrm{M}_{2}$ receptor subtypes in isolated guinea pig trachea and lung smooth muscle, and that it could be used in the treatment of COPD in the future. ${ }^{23}$

Interestingly, a recent study has shown that polyinosinic-polycytidylic acid, a synthetic analog of double-stranded RNA and a ligand for $\mathrm{TLR}_{3},{ }^{24}$ when internalized by airway smooth muscle cells, differentially regulates $M_{2} R$ and $M_{3} R$ expression and function by interacting with $\mathrm{TLR}_{3} \cdot{ }^{25}$ These observations suggest that the ability of polyinosinic-polycytidylic acid to decrease $M_{2} R$ expression and increase $M_{3} R$ expression via an effect on $\mathrm{TLR}_{3}$, expressed in airway smooth muscle cells may have important implications in the development of airway hyperactivity. The decrease in $\mathrm{M}_{2} \mathrm{R}$ would attenuate cholinergic inhibition of adenylate cyclasedependent bronchodilation, representing an indirect effect of bronchoconstriction. The increase in $M_{3} R$ would enhance sensitivity to acetylcholine and promote bronchoconstriction. Collectively, viral double-stranded RNA may directly modulate cholinergic responses of airway smooth muscle cells via the $\mathrm{TLR}_{3}$ pathway.

$\mathrm{PHC}$ has also been seen to decrease NF- $\mathrm{KB}$ expression in the brain after cerebral ischemia-reperfusion injury. ${ }^{5}$ $\mathrm{Li}$ et al investigated the protective effect of $\mathrm{PHC}$ on cytokines released in pediatric patients sustaining lung injury after cardiopulmonary bypass surgery for congenital heart disease, and showed that the protective effects of PHC in the lung were related to inhibition of release of a number of cytokines, including TNF- $\alpha$, interleukin- 6 , interleukin- 8 , and metalloproteinase- $9 .{ }^{26}$ On other hand, Zhang et al investigated the protective effects of $\mathrm{PHC}$ in mice with sepsis and showed that treatment with PHC $0.45 \mathrm{mg} / \mathrm{kg}$ markedly decreased TNF- $\alpha$ levels, malondialdehyde content, and inducible nitric oxide synthase mRNA expression, and enhanced superoxide dismutase activity $(P<0.05$ and

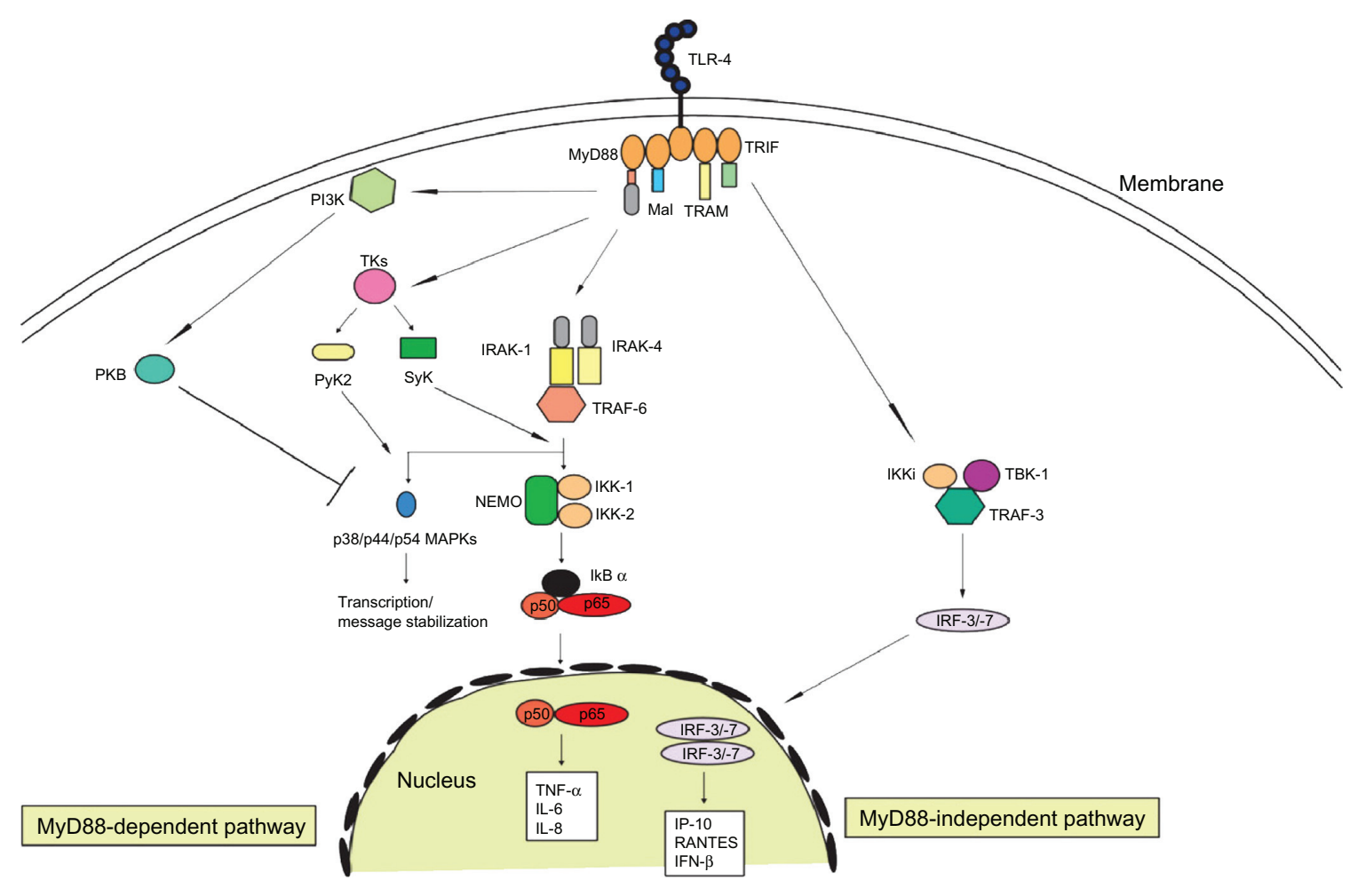

Figure I Toll-like receptor 4 signal pathway.

Abbreviations: TLR-4, toll-like receptor 4; MyD88, myeloid differentiation factor 88; TRIF, TIR-domain-containing adapter-inducing interferon- $\beta$; Mal, MyD88-adapter-like; TRAM, TRIF-related adaptor molecule; TRAF, TNF-receptor-associated factor; PI3K, phosphoinositide 3-kinase; TKs, protein tyrosine kinases; PyK2, protein tyrosine kinase 2; SyK, spleen tyrosine kinase; IRAK, IL-IR-associated kinases; MAPKs, mitogen-activation protein kinases; IKK, IkappaB kinase; PKB, protein kinase B; NEMO, NF-KB essential modulator; NF-KB, nuclear transcription factor kappa-B; TGF, transforming growth factor; MKK, mitogen-activated protein kinase kinase; IRF, IFN regulatory factor; RANTES, Regulated on activation normal T expressed and secreted; TNF, Tumor necrosis factor; IL, interleukin; INF, interferon; IP-I0, interferon-gamma inducible protein I0. 
$P<0.01$, respectively) and that $\mathrm{PHC}$ might have a protective effect against sepsis. ${ }^{27}$

Some of the molecular mechanisms of PHC have been shown to be involved in expression of NF- $\mathrm{KB}$, cytokine TNF- $\alpha$, interleukin- 6 , and interleukin- 8 , and are similar to those described for intracellular signaling by TLRs, whether dependent or independent of MyD88, as shown in Figure 1. $\mathrm{Wu}$ et al recently investigated the effects of PHC on the expression of $\mathrm{TLR}_{4}$ and the inflammatory response in the setting of pulmonary contusion induced by blunt chest trauma, suggesting that $\mathrm{PHC}$ has a protective anti-inflammatory effect in traumatic lung injury via inhibition of the $\mathrm{TLR}_{4}$ pathway and decreasing myeloperoxidase activity and expression of TNF- $\alpha$, interleukin- 6 , and $\mathrm{TLR}_{4}{ }^{28}$ The effects of PHC on TLRs are also being investigated in a rat model of COPD and asthma in our laboratory, with determination of MyD88 and TRIF expression. Our preliminary as-yet unpublished findings are that PHC can regulate the expression of MyD88 and TRIF in the respiratory tract of the rat, suggesting that PHC might act on TLRs. Further, because PHC can block muscarinic receptors, some clinical research has also demonstrated that PHC has curative effects in pulmonary dysfunction associated with COPD. ${ }^{29}$

Increased cell numbers in the innate immune system is one of the hallmarks of chronic inflammation in COPD. These cells are mostly neutrophil granulocytes which are attracted as a result of release of mediators by activated epithelial cells and resident cells of the monocyte/macrophage lineage at the air/blood barrier of the alveoli and in the small conducting airways. Activation of these cells at the site of inflammation may trigger airway remodeling. In addition, it has been suggested that chemokines, which attract neutrophils, act directly on fibroblasts and smooth muscle cells, thereby promoting airway remodeling. ${ }^{30}$

Parasympathetic nerves are the main source of autonomic innervation in the airways. Release of acetylcholine from parasympathetic nerves activates muscarinic receptors present on airway smooth muscle and submucosal glands, causing bronchoconstriction and mucus secretion, which are the main symptoms of COPD. In addition to this signal transduction pathway in the parasympathetic nervous system, it has been shown that other cell types, eg, bronchial epithelial cells and alveolar macrophages, are responsive to acetylcholine stimulation, resulting in release of chemotactic factors which trigger migration of granulocytes. This mechanism may maintain chronic inflammation of the airways, along with other physical and chemical triggers, such as cigarette smoke. ${ }^{31-33}$

\section{Conclusion}

We postulate that PHC has an anti-inflammatory function and may regulate the release of chemotactic factors by TLRs from epithelial cells and macrophages. This effect is likely to be mediated by TLRs in the lung via muscarinic acetylcholine receptors on the cells involved in regulation of the innate immune response. In conclusion, $\mathrm{PHC}$ may be a promising candidate for the treatment of COPD in the future as a result of its ability to attenuate TLRs.

\section{Acknowledgments}

This work was funded by the Science and Technology Pillar Program of Sichuan Province in 2009 (2009SZ0226), the Health Department of Sichuan Province (100491), and the Chengdu City Science and Technology Project (11PPYB010SF-289).

\section{Disclosure}

The authors report no conflicts of interest in this work.

\section{References}

1. Han XY, Liu H, Liu CH, et al. Synthesis of the optical isomers of a new anticholinergic drug, penehyclidine hydrochloride (8018). Bioorg Med Chem Lett. 2005;15:1979-1982.

2. Wang YA, Zhou WX, Li JX, et al. Anticonvulsant effects of phencynonate hydrochloride and other anti-cholinergic drugs in soman poisoning neurochemical mechanisms. Life Sci. 2005;78: 210-223.

3. Xiao HT, Liao Z, Mo ZJ. Progress in pharmacokinetics of penehyclidine hydrochloride. Chin J New Drugs. 2009;18:887-890.

4. Chen XZ. Penehyclidine hydrochloride. Cent S Pharm. 2003;1: 188-189.

5. Ma TF, Rong J, Jing Z, et al. Protective effects of penehyclidine hydrochloride on transient forebrain ischemia reperfusion injury in gerbils. Chin J Clin Pharmacol Ther. 2006;11:453-457.

6. Cao FS, Huang JH, Tao ZX, et al. Effects of penehyclidine hydrochloride on the expression of nuclear factor- $\kappa \mathrm{B}$ in rats after acute global cerebral ischemia/reperfusion. Ling Nan J Emerg Med. 2006;11:7-9.

7. Qiao JZ, Yang SL, Zhen ZJ, et al. Study on pharmacokinetics of penehyclidine hydrochloride in mice. Chin Pharm. 2003;38:942-944.

8. Gross NJ. Anticholinergic agents in asthma and COPD. Eur J Pharmacol. 2006;533:36-39.

9. Rabe KF, Hurd S, Anzueto A, et al. Global strategy for the diagnosis, management, and prevention of chronic obstructive pulmonary disease: GOLD executive summary. Am J Respir Crit Care Med. 2007;176: 532-555.

10. Akira S. Toll-like receptors and innate immunity. Adv Immunol. 2001; 78:1-56

11. Underhill DM, Ozinsky A. Toll-like receptors: key mediators of microbe detection. Curr Opin Immunol. 2002;14:103-110.

12. Takeda K, Kaisho T, Akira S. Toll-like receptors. Annu Rev Immunol. 2003;21:335-376.

13. Sarir H, Henricks PA, van Houwelingen AH, et al. Cells, mediators and Toll-like receptors in COPD. Eur J Pharmacol. 2008;585:346-353.

14. Stowell NC, Seideman J, Raymond HA, et al. Long-term activation of TLR3 by poly (I:C) induces inflammation and impairs lung function in mice. Respir Res. 2009;10:43.

15. Racke K, Matthiesen S. The airway cholinergic system: physiology and pharmacology. Pulm Pharmacol Ther. 2004;17:181-198. 
16. Struckmann N, Schwering S, Wiegand S, et al. Role of muscarinic receptor subtypes in the constriction of peripheral airways, studies on receptor deficient mice. Mol Pharmacol. 2003;64:1444-1451.

17. Fisher JT, Vincent SG, Gomeza J, et al. Loss of vagally mediated bradycardia and bronchoconstriction in mice lacking $\mathrm{M}_{2}$ or $\mathrm{M}_{3}$ muscarinic acetyl-choline receptors. FASEB J. 2004;18:711-713.

18. Profita M, Bonanno A, Siena L, et al. Acetylcholine mediates the release of IL-8 in human bronchial epithelial cells by a NFkB/ERK-dependent mechanism. Eur J Pharmacol. 2008;582:145-153.

19. Pavlov VA, Tracey KJ. Controlling inflammation: the cholinergic anti-inflammatory pathway. Biochem Soc Trans. 2007;34: 1037-1040.

20. Niu Z, Zhao DL, Liu CG. The effects of a new cholinolytic-8018 and its optical isomers on the central muscarinic and nicotinic receptors. Arch Int Pharmacodyn Ther. 1990;304:64-74.

21. Jacoby DB, Fryer AD. Anticholinergic therapy for airway diseases. Life Sci. 2001;68:2565-2572.

22. Xiao HT, Liu P, Xie JP, et al. Anti-asthmatic effects of penehyclidine hydrochloride aerosol on guinea pig and rabbit. West Chin J Pharmac Sci. 2006;21:358-360.

23. Xiao HT, Liao Z, Meng XM, et al. Effects of the selective muscarinic receptor antagonist penehyclidine hydrochloride on the respiratory tract. Pharmazie. 2009;64:337-341.

24. Alexopoulou L, Holt AC, Medzhitov R, et al. Recognition of doublestranded RNA and activation of NF- $\kappa$ B by Toll-like receptor 3. Nature. 2001;413:732-738.
25. Morishima H, Kajiwara K, Akiyama K, Yanagihara Y. Ligation of toll-like receptor 3 differentially regulates $M_{2}$ and $M_{3}$ muscarinic receptor expression and function in human airway smooth muscle cells. Int Arch Allergy Immunol. 2008;145:163-174.

26. Li J, Gan LG, Cao H, et al. Protective mechanisms of penehyclidine hydrochloride in lung injury after CPB in pediatrics. Anesthesiology. 2008;109:A154

27. Zhang J, Wang YL, Wang CY, et al. Protective effects of penehyclidine hydrochloride on septic mice and its mechanism. Shock. 2007;28: 727-732.

28. Wu XJ, Xia ZY, Wang LL, et al. Effects of penehyclidine hydrochloride on pulmonary contusion from blunt chest trauma in rats. Injury. 2012;43: 232-236.

29. Tao YJ, Chen JR, Zhu J, et al. The clinical applications of penehyclidine hydrochloride in patients with AECOPD. Chin J Emerg Med. 2006;15: 255-259.

30. Gosens R, Zaagsma J, Meurs H, et al. Muscarinic receptor signaling in the pathophysiology of asthma and COPD. Respir Res. 2006;7:73.

31. Coulson FR, Fryer AD. Muscarinic acetylcholine receptors and airway diseases. Pharmacol Ther. 2003;98:59-69.

32. Koyama S, Sato E, Nomura H, et al. Acetylcholine and substance P stimulate bronchial epithelial cells to release eosinophil chemotactic activity. J Appl Physiol. 1998;84:1528-1534.

33. Sato E, Koyama S, Okubo Y, et al. Acetylcholine stimulates alveolar macrophages to release inflammatory cell chemotactic activity. Am J Physiol. 1998;274:L970-L979.
Drug Design, Development and Therapy

\section{Publish your work in this journal}

Drug Design, Development and Therapy is an international, peerreviewed open-access journal that spans the spectrum of drug design and development through to clinical applications. Clinical outcomes, patient safety, and programs for the development and effective, safe, and sustained use of medicines are a feature of the journal, which

\section{Dovepress}

has also been accepted for indexing on PubMed Central. The manuscript management system is completely online and includes a very quick and fair peer-review system, which is all easy to use. Visit http://www.dovepress.com/testimonials.php to read real quotes from published authors.

Submit your manuscript here: http://www.dovepress.com/drug-design-development-and-therapy-journal 